\title{
Using individual stated-preferences to optimize HIV self-testing service delivery among men who have sex with men (MSM) in Malaysia: results from a conjoint-based analysis
}

Roman Shrestha $a^{1,2^{*}}$ (D) Haridah Alias ${ }^{2,3}$, Li P. Wong ${ }^{2,3}$, Frederick L. Altice ${ }^{1,2}$ and Sin H. Lim ${ }^{2,3}$

\begin{abstract}
Background: HIV self-testing (HIVST) has the potential to improve HIV testing uptake and frequency for key populations like MSM who experience multiple barriers accessing clinic-based HIV testing. In the absence of HIVST in Malaysia, there is no guidance to inform HIVST delivery. This study investigated the acceptability of HIVST and preferences about the HIVST service delivery approaches using a standardized stated preference method.
\end{abstract}

Methods: A cross-sectional online survey conducted between January and April 2019 assessed the interest in HIVST in 544 MSM in Malaysia. Participants ranked eight hypothetical HIVST service delivery program elements with varied combinations of six, two-level HIVST service delivery program attributes (cost, privacy, accuracy, kit collection site, kit type, and testing support). SPSS conjoint procedure was used to estimate the relative importance of each attribute and preference across eight possible HIVST service delivery programs.

Results: Overall, $70.4 \%$ had previously tested for HIV, and of those, $64.0 \%$ had done so in the past 6 months (45.0\% of all participants). Of all the participants, $25.2 \%$ reported having used HIVST previously. The acceptability for HIVST service delivery models ranged from 44.9 to $77.1 \%$, with mean acceptability of $56.2 \%$ across the eight hypothetical HIVST distribution scenarios. The HIVST service delivery scenario with the highest acceptability had the following attributes: no cost (free), anonymity (name not required), 99-100\% accuracy, home-delivered, fingerstick, and testing support using telephone hotline or texting. HIVST cost was the most important attribute (relative importance score: RIS $=19.30)$ associated with acceptability, followed by anonymity $(R I S=18.41)$, accuracy $(R I S=17.33)$, kit delivery $(R I S=16.99)$, fingerstick kit $(R I S=15.86)$, and support $(R I S=12.08)$.

* Correspondence: roman.shrestha@yale.edu

'Section of Infectious Disease, Department of Internal Medicine, Yale School of Medicine, 135 College Street, Suite 323, New Haven, CT 06510, USA

${ }^{2}$ Centre of Excellence for Research in AIDS (CERiA), Faculty of Medicine, University of Malaya, Kuala Lumpur, Malaysia

Full list of author information is available at the end of the article

(c) The Author(s). 2020 Open Access This article is licensed under a Creative Commons Attribution 4.0 International License, which permits use, sharing, adaptation, distribution and reproduction in any medium or format, as long as you give appropriate credit to the original author(s) and the source, provide a link to the Creative Commons licence, and indicate if changes were made. The images or other third party material in this article are included in the article's Creative Commons licence, unless indicated otherwise in a credit line to the material. If material is not included in the article's Creative Commons licence and your intended use is not permitted by statutory regulation or exceeds the permitted use, you will need to obtain permission directly from the copyright holder. To view a copy of this licence, visit http://creativecommons.org/licenses/by/4.0/ The Creative Commons Public Domain Dedication waiver (http://creativecommons.org/publicdomain/zero/1.0/) applies to the data made available in this article, unless otherwise stated in a credit line to the data. 
(Continued from previous page)

Conclusions: Acceptability for HIVST in Malaysian MSM was high but differed markedly by a number of HIVST delivery scenarios and attributes. These findings could be relevant as the Malaysian Ministry of Health is in the process of developing a regulatory framework for ensuring the quality of kits, as well as policies supporting safe use while broader implementation under national AIDS programs.

Keywords: HIV, HIV self-testing, Men who have sex with men, Implementation science, Conjoint analysis, Malaysia

\section{Background}

HIV testing is the first step towards achieving UNAID's 95-95-95 targets [1] as well as for bridging the HIV prevention gap to scale-up pre-exposure prophylaxis (PrEP) in key populations [2]. For key population groups like men who have sex with men (MSM), however, HIV testing uptake is often low due to multilevel factors like fear, stigma and discrimination, criminalization, and disclosure of sexual/gender identity, lack of anonymity, and concerns about confidentiality [3-8]. In Malaysia, a middle-income country with a Muslim majority, same-sex behaviors are criminalized in both secular and Sharia laws, resulting in high levels of stigma and de facto discrimination. Consequently, MSM in Malaysia inadequately test, which has thwarted scale-up of effective HIV testing, prevention, and treatment programs for the lesbian, gay, bisexual, and transgender (LGBT) community.

Sexual health programs have mainly focused on mandatory HIV testing among Muslim couples planning to marry. Consequently, HIV prevention and treatment programs are inadequately designed for MSM, who now account for most new HIV infections in Malaysia [9]. With only $61.6 \%$ of Malaysian MSM having ever tested for HIV and less than half (44.5\%) tested in the past 12 months [10], innovations in HIV testing are needed. In an effort to address gaps in delivering HIV testing services, to achieve national and global testing targets, the World Health Organization (WHO) recommends and guides HIV self-testing (HIVST) to supplement traditional facility and community outreach testing [11]. HIVST offers an alternative to other testing strategies, including reaching new MSM and increase testing frequency to facilitate early HIV detection and treatment and prevent new infections [12, 13]. HIVST increases convenience, privacy, and confidentiality, but its uptake may be limited by cost for some MSM, particularly in Malaysia, concerned with legal constraints and face high rates of stigma and discrimination.

While HIVST research has increased globally, no empirical studies have been conducted in Malaysia. HIVST is currently not licensed in Malaysia, and the country does not have any formal regulation of HIVST kits yet. However, unregulated HIVST kits are available for purchase at several pharmacies nationwide and are also widely available through the internet $(\mathrm{RM} 20=\sim$ USD5).
As the Malaysian Ministry of Health develops its national HIVST policy to expand HIV testing in key populations, empirical evidence to guide nation-wide HIVST strategy is critical. Specifically, MSM are heterogeneous in terms of their preferences about HIV testing, and as HIVST becomes an option for them, it is crucial to understand elements that are important for HIVST programs that have the potential for jumpstarting the HIV treatment and prevention cascades [14]. To better understand preferences about HIVST in MSM, we examined the acceptability of HIVST and relative preferences about the elements of HIVST delivery, using a standardized stated preference method (conjoint-based analysis; CBA) to assess how Malaysian MSM value various attributes of hypothetical HIVST service delivery models.

\section{Methods \\ Study design and participants}

In preparation for introducing HIVST, a cross-sectional online survey to assess the willingness to adopt HIVST in Malaysia was conducted between January and April 2019. Individuals are eligible if they: i) are aged 18 years or older; ii) are Malaysian citizens; iii) are biologically male who reported having sex with other men in the past 12 months or being a transgender woman (male sex assigned at birth and reporting gender identity as female); and iv) self-reported HIV-negative or HIV status unknown. The study was initially planned to include both MSM and TGW in Malaysia. However, we were unable to recruit enough TGW to include them in our analysis $(n=6)$. We therefore excluded 6 TGW participants from the analysis to ensure the generalizability of the findings to the Malaysian MSM community.

\section{Study procedures}

Participants were recruited using a combination of both online and offline recruitment strategies. Specifically, participants were recruited through social media popular among MSM in Malaysia (e.g., Grindr, Hornet), AIDS and LGBT-friendly NGO social media profiles, and peer referrals. A standardized script was used to message prospective participants. Those interested in participating received a web link directing them to the online survey hosted by Qualtrics, where eligibility criteria were 
specified. Each eligible participant voluntarily completed the IRB-approved online consent form before initiating the survey. On average, it took $12 \mathrm{~min}$ for the participants to complete the anonymous online survey. Participation in the survey was voluntary, and participants were not paid for completing the survey. The study protocol and the consent form were approved by the University of Malaya Research Ethics Committee (UMREC).

\section{Study measures \\ Participant characteristics}

included age, gender identity, ethnicity, relationship status, educational attainment, employment, and income. Participants self-reported engagement in HIV risk behaviors (i.e., sexual- and drug-related factors), history of HIV testing practices, and stigma and discrimination related to sexual orientation. Participants were also asked about their awareness of HIVST and previous use of HIVST.

\section{Conjoint-based analysis (CBA)}

Stated preference methods are increasingly being used to enable policymakers to quantify the values that key populations attach to each attribute of service delivery and to determine which combination of features is likely to result in optimal health outcomes in this stigmatized and hard-to-reach group [15].

We used a full-profile CBA design to quantify the importance of various attributes of the HIVST program. CBA is an established statistical technique of assessing consumer preferences in market research, and it is increasingly being applied to evaluate health-care intervention [16-18].

We identified six dichotomous attributes relevant to HIVST program, that included: cost (free vs. pay some money); privacy (name not required vs. name required); accuracy (99-100\% vs. 95\%); kit collection site (home-delivered vs. at a pharmacy); kit type (fingerstick vs. oral swab); and testing support (telephone hotline/texting vs. online videos). The array of attributes and their dichotomous values were developed based on inputs from experts working with the target populations and published research on HIVST acceptability [19-24]. The six dichotomous HIVST attributes yielded $64\left(2^{6}=64\right)$ different HIVST distribution conjoints (scenarios). We employed a fractional factorial orthogonal design [25] to generate a subset of representative scenarios (each attribute/level combination appears the same number of times) given the high burden on participants to rate every scenario. This method enabled us to reduce the number of HIVST service delivery scenarios from 64 to 8 .
The hypothetical HIVST distribution scenarios were presented simultaneously after the participants were provided with a brief description of the HIVST attributes and their values. Participants were then asked to rank the eight scenarios in terms of acceptability from 1 ("most likely to use") to 8 ("least likely to use"). None of the scenarios could share the same value (Fig. 1). The scenarios were presented randomly using a randomization feature of Qualtrics to prevent order effect bias.

\section{Statistical analysis}

Among the 550 participants recruited, data for 544 were analyzed (6 participants were TGW and excluded from the analysis). We computed descriptive statistics, including frequencies and percentages for categorical variables and means and standard deviations for continuous variables. We used the chi-square test and t-test to compare the frequencies (or means) for those willing and unwilling to use HIVST. We then used CBA to explore the acceptability of HIVST delivery scenarios. The acceptability of each HIVST distribution scenario was derived by averaging individual HIVST distribution model acceptability ratings across respondents. Ratings from each HIVST distribution model was transformed into a 0-100 scale, whereby "most likely to use" $=100$ and "least likely to use" $=0$. We employed the SPSS Conjoint procedure to generate marginal utility scores (MUS; a measure of preference of each factor level) for each attribute level [26] and the relative importance score (RIS; a measure of the importance of the attribute) $[27,28]$.

\section{Results}

\section{Participant characteristics}

Table 1 provides a summary of the characteristics of 544 participants. Most participants were single (75.2\%), university graduates (87.1\%), and currently employed (71.5\%). In terms of sexual behaviors, $84.0 \%$ of participants reported having anal sex with another man in the past six months, with $79.6 \%$ involved in condomless sex. Overall, $70.4 \%$ had previously tested for HIV, and of those, $64.0 \%$ had done so in the past 6 months $(45.0 \%$ of all participants). Of all the participants, $25.2 \%$ reported having used HIVST previously. Most participants agreed that they feel discriminated against by either mistreatment or negative judgment by healthcare providers if they disclose their sexual identity (68.8\%), whereas half $(50.2 \%)$ agreed that they feel embarrassed when peers (e.g., friends regardless of sexual orientation) discover that they are getting tested for HIV. Notably, there was a significantly increased likelihood of being willing to use HIVST based on their sexual orientation $(p=0.001)$, ethnicity $(p=0.001)$, engagement in anal sex with another man in the last 6 months $(p=0.009)$, prior HIV testing $(p=0.049)$, and previous use of an HIVST kit $(p<0.001)$. 


\begin{tabular}{|c|c|c|c|}
\hline \multirow{2}{*}{$\begin{array}{l}\text { Scenario A } \\
\text { Cost: Pay some money } \\
\text { Kit collection site: Home delivery } \\
\text { Privacy: Name required }\end{array}$} & \multirow[b]{2}{*}{$\begin{array}{l}\text { Testing support: Online Videos } \\
\text { Accuracy: } 95 \% \\
\text { Kit type: Fingerstick }\end{array}$} & \multirow{2}{*}{$\begin{array}{l}\text { Scenario B } \\
\text { Cost: Pay some money } \\
\text { Kit collection site: Home delivery } \\
\text { Privacy: Name not required }\end{array}$} & \multirow[b]{2}{*}{$\begin{array}{l}\text { Testing support: Telephone hotline/Texting } \\
\text { Accuracy: } 95 \% \\
\text { Kit type: Oral swab }\end{array}$} \\
\hline & & & \\
\hline \multirow{2}{*}{$\begin{array}{l}\text { Scenario C } \\
\text { Cost: Pay some money } \\
\text { Kit collection site: At a pharmacy } \\
\text { Privacy: Name required }\end{array}$} & & \multirow{2}{*}{$\begin{array}{l}\text { Scenario D } \\
\text { Cost: Free } \\
\text { Kit collection site: Home delivery } \\
\text { Privacy: Name required }\end{array}$} & \\
\hline & $\begin{array}{l}\text { Testing support: Telephone hotline/Texting } \\
\text { Accuracy: } 99-100 \% \\
\text { Kit type: Oral swab }\end{array}$ & & $\begin{array}{l}\text { Testing support: Online Videos } \\
\text { Accuracy: } 99-100 \% \\
\text { Kit type: Oral swab }\end{array}$ \\
\hline \multirow{2}{*}{$\begin{array}{l}\text { Scenario E } \\
\text { Cost: Free } \\
\text { Kit collection site: At a pharmacy } \\
\text { Privacy: Name required }\end{array}$} & & \multirow{2}{*}{$\begin{array}{l}\text { Scenario F } \\
\text { Cost: Free } \\
\text { Kit collection site: Home delivery } \\
\text { Privacy: Name not required }\end{array}$} & \\
\hline & $\begin{array}{l}\text { Testing support: Telephone hotline/Texting } \\
\text { Accuracy: } 95 \% \\
\text { Kit type: Fingerstick }\end{array}$ & & $\begin{array}{l}\text { Testing support: Telephone hotline/Texting } \\
\text { Accuracy: } 99-100 \% \\
\text { Kit type: Fingerstick }\end{array}$ \\
\hline \multirow{2}{*}{$\begin{array}{l}\text { Scenario G } \\
\text { Cost: Pay some money } \\
\text { Kit collection site: At a pharmacy } \\
\text { Privacy: Name not required }\end{array}$} & & \multirow{2}{*}{$\begin{array}{l}\text { Scenario } \mathrm{H} \\
\text { Cost: Free } \\
\text { Kit collection site: At a pharmacy } \\
\text { Privacy: Name not required }\end{array}$} & \\
\hline & $\begin{array}{l}\text { Testing support: Online Videos } \\
\text { Accuracy: } 99-100 \% \\
\text { Kit type: Fingerstick }\end{array}$ & & $\begin{array}{l}\text { Testing support: Online Videos } \\
\text { Accuracy: } 95 \% \\
\text { Kit type: Oral swab }\end{array}$ \\
\hline
\end{tabular}

Fig. 1 Example of full-profile conjoint task (hypothetical HIV self-testing program scenarios)

\section{Conjoint analysis}

Table 2 presents the acceptability scores of each HIVST service delivery scenario. The acceptability ranged from 44.9 to $77.1 \%$, with overall mean acceptability of $56.2 \%$. The top-rated HIVST service delivery scenario included no cost (free), anonymous (name not required to receive HIVST kit), 99-100\% effective, home-delivered, finger stick (saliva-based), and the ability to receive pre-test counseling support anonymously.

Table 3 presents the marginal utility of each attribute on overall acceptability. The findings show that the cost associated with HIVST was the single most important attribute. Our sample reported higher acceptability if the HIVST kit was offered free of charge $(M U S=-0.906)$, compared to paying for the kit $(M U S=-1.812)$, yielding a net RIS of 19.30. Privacy had the second-greatest impact on acceptability with an overall RIS of 18.41. Participants preferred the anonymous HIVST program $(M U S=0.432)$ to the one which requires providing a name to receive the HIVST kit $(M U S=-0.432)$. Accuracy of HIVST had the third-greatest impact on HIVST acceptability. Participants reported higher acceptability for HIVST when it was $99-100 \%$ effective $(M U S=1.471)$ compared with $95 \%$ effective (MUS $=0.735)$, yielding a RIS of 17.33. Kit collection site $(R I S=16.99)$, kit type $(R I S=15.86)$, and support $(R I S=12.08)$ had relatively low influence on HIVST acceptability. Compared to buying it over the counter $(M U S=-0.241)$, participants preferred having it delivered to their home $(M U S=0.241)$. Participants preferred fingerstick HIVST kit $(M U S=$ 0.064 ) over oral swab testing (MUS $=-0.064$ ). Receiving testing and counseling anonymously (telephone hotline or WhatsApp texting $(M U S=0.027)$ rather than using online videos $(M U S=-0.027)$ was marginally preferred (Table 3 and Fig. 2).

\section{Discussion}

To the best of our knowledge, this is the first study to assess the acceptability of HIVST using CBA among MSM that quantifies key attributes associated with HIVS $\mathrm{T}$ acceptability in this key population. Key findings from this study was that MSM had suboptimal rates of recent HIV testing (45.0\% in the past six months), and the CBA provided useful insights as Malaysia struggles to improve HIV testing in the country. This study further offers important insights into the potential use of HIVST by MSM in Malaysia. Although the minority of our sample had previously used the HIVST, we observed a high willingness to use HIVST, a finding observed elsewhere in MSM [29-31]. Given the low current HIV testing rates in this group with a high need for testing and concomitant linkage to prevention and treatment services, innovations in HIV testing, including HIVST, may fill an important gap in HIV prevention and treatment.

Using the CBA, we ranked the weighted importance of HIVST attributes among Malaysian MSM, who remain highly stigmatized and marginalized from existing HIV prevention services. The findings revealed significant variations in participants' attitudes and preferences of HIVST service delivery approaches that collectively or individually may strengthen efforts to scale-up HIVST in the Malaysian context. HIVST acceptability exceeded $60 \%$ for two case scenarios (6 and 4 ). Three key attributes were central to both scenarios - no cost, testing anonymity, and high efficacy - with other attributes (kit collection site, kit type, and counseling support) varying between the two scenarios. These attributes collectively influenced $\sim 55 \%$ of all stated preferences. One discrete choice experiment (DCE) in China assessed HIV testing preferences generally (not just HIVST) among MSM and has some findings that are consistent with ours. Their 
Table 1 Participant characteristics of Malaysian MSM, stratified by willingness to use HIV self-testing kit $(2019, N=544)$

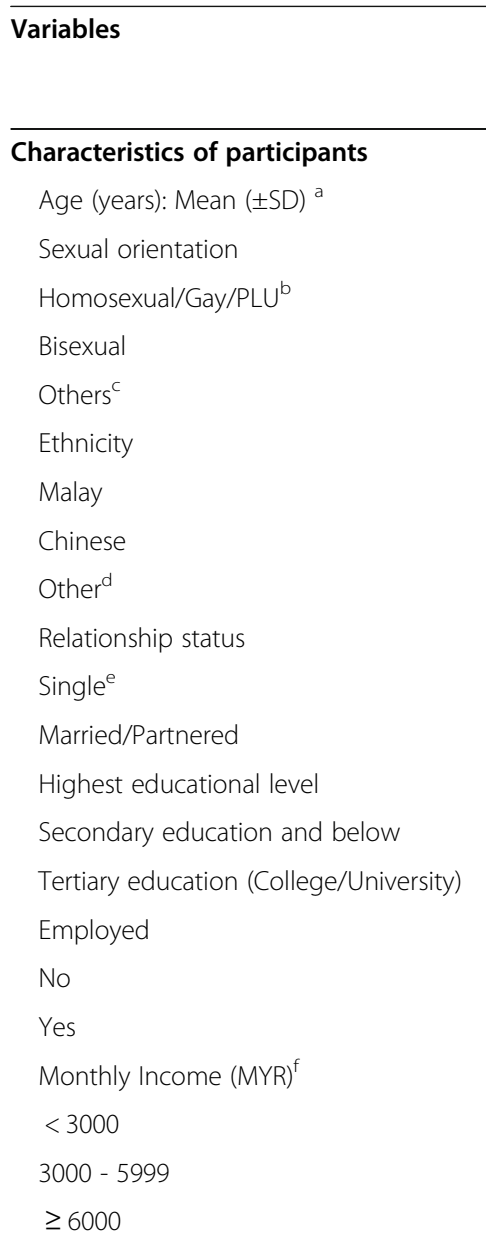

\begin{tabular}{ll}
$\begin{array}{l}\text { Entire Sample } \\
(N=544)\end{array}$ & $\begin{array}{l}\text { Willing to use HIVST } p \\
(n=405) \text { i } n(\%)\end{array}$ \\
\cline { 1 - 1 } Frequency \% &
\end{tabular}

Characteristics of participants

$\begin{array}{llll}30.6( \pm 8.0) & & 30.2( \pm 7.6) & 0.008 \\ & & & 0.001 \\ 432 & 79.4 & 320(58.8) & \\ 98 & 18.0 & 80(14.7) & \\ 14 & 2.6 & 5(0.9) & \end{array}$

\section{Sexual Behavior Characteristics}

Any anal intercourse with another man (last 6 months)

No

87

$16.055(10.1)$

Yes

Condomless anal sex (last 6 months)

457

$84.0350(64.3)$

No

$n=457$

$50.0220(40.4)$

272

$33.1 \quad 117(21.5)$

92

$16.968(12.5)$

$409 \quad 75.2 \quad 308(56.6)$

$135 \quad 24.8 \quad 97(17.8)$

Yes

93

$20.476(16.6)$

364

$79.6274(60.0)$

Average number of male sexual partners (last 6 months): Mean $( \pm \mathrm{SD})^{\mathrm{a}}$

$5.1( \pm 12.1)$

$$
5.3( \pm 13.6)
$$

Ever engaged in transactional sex ${ }^{9}$

$n=105$

0.727

No

483

$88.8357(65.6)$

Yes

61

$11.248(8.8)$

Ever used recreational drugs before or during sex ${ }^{\mathrm{h}}$

Yes

\section{Prior HIV testing}

Ever been tested for HIV

Yes 
Table 1 Participant characteristics of Malaysian MSM, stratified by willingness to use HIV self-testing kit (2019, N=544) (Continued)

\begin{tabular}{|c|c|c|c|c|}
\hline \multirow[t]{2}{*}{ Variables } & \multicolumn{2}{|c|}{$\begin{array}{l}\text { Entire Sample } \\
(N=544)\end{array}$} & \multirow[t]{2}{*}{$\begin{array}{l}\text { Willing to use HIVST } \\
(n=405){ }^{i} n(\%)\end{array}$} & \multirow[t]{2}{*}{$p$} \\
\hline & Frequency & $\%$ & & \\
\hline Less than 6 months ago & 245 & 64.0 & $174(45.4)$ & \\
\hline $6-12$ months ago & 66 & 17.2 & $53(13.8)$ & \\
\hline Over 12 months ago & 72 & 18.8 & 49 (12.8) & \\
\hline Ever used an HIV self-testing kit & & & & $<0.001$ \\
\hline No & 407 & 74.8 & $283(52.0)$ & \\
\hline Yes & 137 & 25.2 & $122(22.4)$ & \\
\hline \multicolumn{5}{|l|}{ Stigma and Discrimination } \\
\hline I feel embarrassed when people relate HIV as "LGBT" disease & 339 & 62.3 & $262(48.2)$ & 0.051 \\
\hline I feel embarrassed when peers discover that I am getting tested for HIV & 273 & 50.2 & $223(41.0)$ & $<0.001$ \\
\hline $\begin{array}{l}\text { I feel discriminated of being mistreated and judged by the healthcare providers if they know } \\
\text { my sexual identity }\end{array}$ & 374 & 68.8 & $292(53.7)$ & 0.004 \\
\hline
\end{tabular}

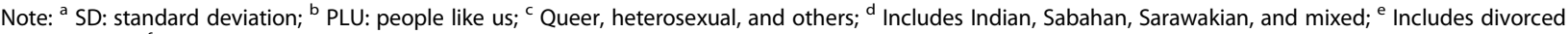
and widowed; ${ }^{f}$ MYR: Malaysian Ringgit; ${ }^{g}$ Received any things or opportunities (e.g., mobile phone, cash, clothes, bag, study or employment opportunity) in exchange for sex; ${ }^{\text {h }}$ Includes crystal meth/"ice", ketamine, ecstasy, poppers, GHB/GBL) before or during anal sex: ${ }^{i}$ HIVST: HIV self-testing

study showed the two key attributes to HIV testing similar to ours and included no cost and testing anonymity [32].

As noted, the cost is the most critical attribute for MSM when considering options for HIVST service delivery. It is not surprising that access to free HIVST (fully subsidized) dominated the individual program attributes, especially given that almost half of the participants in this sample (46.8\%) preferred spending less than RM20 ( USD 5 ) as the maximum price they would pay for one unit of HIVST kit. When cost is factored into most CBA assessments, it typically dominates since people generally appear to prefer not to pay for services that they feel should be covered by the government, health insurance, or other funders [19, 20, 32, 33]. As the market of HIVST evolves, this finding may alter as MSM gain experience with HIVST, especially as donor agencies and governments make decisions on how much to subsidize the prices for the HIVST, if at all.

Importantly, participants preferred to access HIVST kits anonymously and have it delivered to home. Findings here indicate that HIVST may have limited appeal to Malaysian MSM if anonymity is not maintained. This aligns with the results from prior studies with key populations in other geographical settings, where participants reported privacy concerns as a barrier to HIV testing in general (not necessarily HIVST) [32, 34]. Though not explored here, these findings point to the perceived high levels of stigma related to being a sexual minority, as observed in this sample. In Malaysia, where anal sex between two consenting adults is criminalized, MSM bear the dual burden of social stigma and discrimination. Consequently, MSM avoid going to hospitals/clinics for fear of disclosing their sexual identity, which entails

Table 2 Acceptability (Mean) of hypothetical HIV self-testing with different attributes in order of decreasing acceptability among Malaysian MSM (2019, N=544)

\begin{tabular}{|c|c|c|c|c|c|c|}
\hline \multirow{2}{*}{$\begin{array}{l}\text { Acceptability } \\
\text { (Mean) }\end{array}$} & \multicolumn{6}{|c|}{ HIV Self-Testing Attributes } \\
\hline & Cost & Kit Collection Site & Privacy & Testing Support & Accuracy (\%) & Kit Type \\
\hline 77.09 & Free & Home delivered & Name not required & Telephone Hotline/Texting & $99-100$ & Fingerstick \\
\hline 62.37 & Free & Home delivered & Name required & Online videos & $99-100$ & Oral swab \\
\hline 59.20 & Free & At a pharmacy & Name not required & Online videos & 95 & Oral swab \\
\hline 57.15 & Pay some money & At a pharmacy & Name not required & Online videos & 99-100 & Fingerstick \\
\hline 52.93 & Pay some money & Home delivered & Name not required & Telephone Hotline/Texting & 95 & Oral swab \\
\hline 48.90 & Free & At a pharmacy & Name required & Telephone Hotline/Texting & 95 & Fingerstick \\
\hline 47.41 & Pay some money & At a pharmacy & Name required & Telephone Hotline/Texting & 99-100 & Oral swab \\
\hline 44.91 & Pay some money & Home delivered & Name required & Online videos & 95 & Fingerstick \\
\hline
\end{tabular}


Table 3 Relative importance and marginal utilities of HIV selftesting attribute levels among Malaysian MSM (2019)

\begin{tabular}{lll}
\hline Attributes & Attribute Levels & RIS $^{\mathbf{a}}$ \\
\hline Cost & Free & 19.30 \\
& Pay some money & \\
Privacy & Name not required & 18.41 \\
& Name required & \\
Accuracy & $99-100 \%$ & 17.33 \\
Kit Collection Site & $95 \%$ & \\
& Home delivered & 16.99 \\
Kit Type & At a pharmacy & \\
& Fingerstick & 15.86 \\
Testing Support & Oral swab & 12.08 \\
& Telephone hotline / Texting & \\
\hline
\end{tabular}

Note: ${ }^{a}$ Relative importance score

stigma and discrimination. As a discreet and convenient approach, HIVST might be most useful in reaching MSM who are reluctant or unable to access traditional venue-based HIV testing services because of concerns about privacy, stigma, and discrimination, and, in some instances, criminalization [8, 35, 36]. Given the social costs associated with disclosing MSM identities and behaviors in Malaysia, it is important for policymakers to take into account that the appeal of HIVST will be severely diminished if MSM are required to provide their name to access HIVST.

While HIVST, when done anonymously, provides an added layer of protection and addresses stigma for MSM, it may leave potential gaps in the HIV treatment and prevention cascades, since testing provides a key step in linkage to either confirmatory testing and associated HIV care followed by ART prescription if test results are positive and to pre-exposure prophylaxis (PrEP) for high-risk MSM without HIV [12, 37-39]. Especially in settings where high levels of stigma toward MSM exist, like in Malaysia, innovative strategies are needed to complement anonymous HIVST delivery with support during testing, accurate interpretation of results, and creative solutions for expeditiously linking MSM to post-test counseling and care. Mobile technology (e.g., smartphone app: HIVSmart!, WeTest) is feasible and acceptable in MSM to promote HIVST and linkage to care following the self-testing, but only when testing was confidential and not anonymous [40, 41]. In our sample,

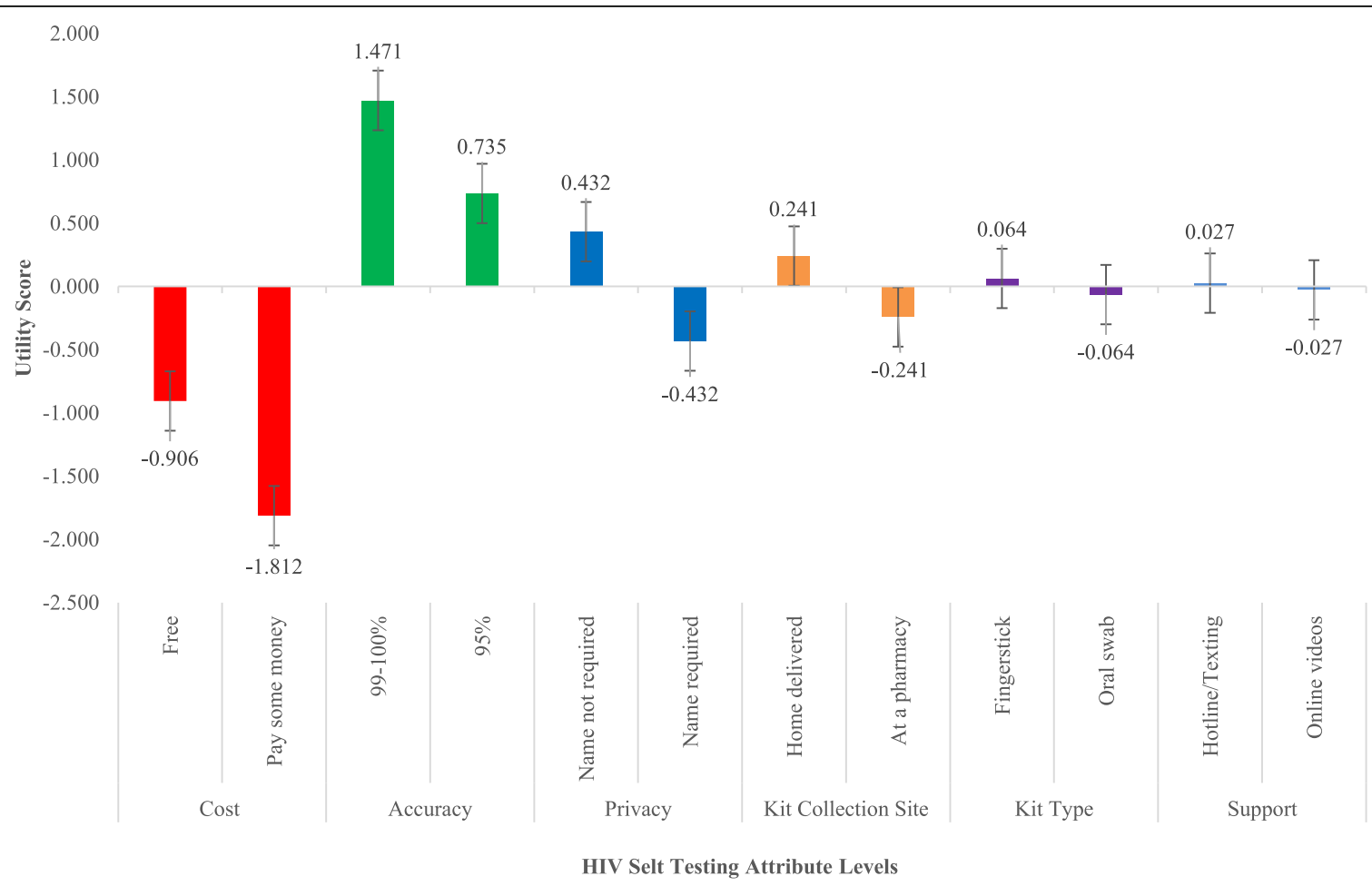

* Constant: 4.756 (0.326), Pearson's R: 0.995, Kendall's tau: 1.00; Marginal utilities, also known as part-worth, of a specific attribute in participants' ranking of the scenarios. They signify the extent to which a specific attribute contributes to the ranking of a scenario.

Fig. 2 Marginal utilities of HIV self-testing attributes' levels among Malaysian MSM (2019). * Constant: 4.756 (0.326), Pearson's R: 0.995, Kendall's tau: 1.00; Marginal utilities, also known as part-worth, of a specific attribute in participants' ranking of the scenarios. They signify the extent to which a specific attribute contributes to the ranking of a scenario 
anonymity was the highest preference attribute for HIVS $\mathrm{T}$ after cost. One potential strategy to balance anonymity in HIVST with adequate linkage to care was learned in the Social Entrepreneurship Model (SET), which allowed anonymous HIV testing, but did so by asking Chinese MSM to pay money upfront (USD 23) to receive their HIVST kit, but refunded after sharing test results via a web portal) [42]. Because cost was the most important attribute in our sample, it is unsure how MSM in the Malaysian context would be willing and/or able to put money upfront for HIVST. One might consider free HIVST, but if kits were delivered to home addresses, it may not be fully anonymous. Alternatively, if they have it delivered to an alternative address, such MSM would need the motivation to provide personal information if they knew that the benefit of linkage to care through disclosure outweighed the risks. Therefore, additional research is needed to identify new strategies that balance cost and anonymity to impact HIV testing, followed by effective linkage to care.

Our data further indicated accuracy as an important attribute, with $99-100 \%$ accuracy being the preferred alternative, as expected. Previous studies have shown that concerns about the accuracy of HIVST as being one of the major barriers to HIVST uptake [8, 43], yet evidence suggests that currently approved HIVST kits have sensitivity and specificity of $99 \%$ or higher [44]. Furthermore, participants expressed a strong preference for bloodbased tests using fingerstick (66.7\% vs. $19.7 \%$ ), although the saliva-based kit is the only HIVST kit prequalified by WHO [45]. Our study identified a preference but did not explicitly say they would not accept saliva-based testing. The preference for the blood-based tests may be due to its greater perceived accuracy and fewer falsenegative test results, as compared to saliva-based tests, as suggested in prior literature $[8,46-48]$. in the absence of a lived experience and personal testimonies of one method over another, it can be challenging to give credence to this preference without further exploration. Given the hypothetical nature of the scenarios presented to the participants, future studies need to verify this finding to facilitate developing the most preferred HIVS $\mathrm{T}$ service delivery model for this population. The emergence in recent years of several new HIVST methods and technologies with increased accuracy may contribute to increasing consistent testing among this group.

Our sample generally preferred virtual interaction (telephone hotline or WhatsApp texting) for counseling support rather than in-person interactions. This preference is supported by the high levels of stigma in MSM and is supported by their preference to maintain anonymity. Moreover, this population of MSM are young and generally prefer technology-based interactions. This method also provides the users with technical support, counseling, and referrals for further HIV testing services, HIV prevention, care and treatment, and other services, including psychosocial, legal support, and violence support, as demonstrated in prior research $[19,49,50]$. This finding, along with the evidence that a large proportion of Malaysian MSM have access to smartphones [10], emphasizes the potential for a telephone hotline or smartphone app-based (e.g., WhatsApp message) platform for counseling. This finding aligns well with prior research [10], indicating the need for innovative approaches, such as mHealth, to scale-up HIVST in this highly stigmatized group.

Our data further indicated that participants were willing to make trade-offs to have the HIVST approach they prefer. For example, participants were willing to use the oral HIVST kit and use online videos for counseling in exchange for not having to disclose their name while receiving the kit. In other instances, participants were willing to pay out-of-pocket and use oral HIVST kit to avoid disclosing their identity while buying the HIVST kit. Although the traditional venue-based HIV testing models have a high impact on HIV testing, we found that low-cost with home delivery HIVST distribution model that allows for anonymous testing may be an important strategy to increase HIV self-testing in key populations that would not otherwise test, such as MSM. Much has been learned from HIVST demonstration programs targeting MSM in the other context $[23,49,51-53]$, and many such lessons, as well as the user stated-preference information from the current study, might be taken into account into the decision-making process to optimize HIVST distribution program among MSM in the Malaysian setting.

Several study limitations must be acknowledged. First, this survey involved CBA but did not incorporate a segmentation analysis. Future studies should better understand that there might be subgroups of MSM who may have different patient-stated preferences. For example, in Ukrainian MSM, younger MSM and those with substance use disorders preferred PrEP delivery methods that differed from their counterparts [54]. Second, this analysis excluded TGW, and the findings should not be generalized for this key population. Further studies of patient preferences for HIVST in TGW should be conducted, even some general information is already available [55]. Third, although a brief explanation about HIVST and its attributes was provided, we do not know the extent to which participants understood every attribute (e.g., cost, privacy, accuracy, kit collection site, kit type, and testing support) while ranking the HIVST program scenarios. This is especially true since there is limited experience and no real testimonials to drive patient preferences. Third, our use of self-report measures may have resulted in participant underreporting or inconsistent reporting (e.g., HIV status) of socially undesirable 
behaviors. Last, and importantly, patient preferences and intentions may not fully be aligned with their practices, suggesting the need to link uptake of HIVST after stating their preferences. Further research is thus warranted to assess the impact of these issues on HIVST acceptability among our sample.

Malaysia has yet to establish guidelines for the use of HIVST. The findings from this study underscore the need to consider participant preferences and key attributes while selecting service delivery models and support tools. This could be relevant as the market for HIVST takes shape in the country, with the Malaysian Ministry of Health in the process of developing a regulatory framework for ensuring the quality of kits, as well as policies supporting safe use while broader implementation under national AIDS programs. Important.

\section{Conclusions}

HIVST offers an alternative to traditional, venue-based testing that could significantly improve HIVST uptake and is ideally situated where stigma related to key populations, HIV, or both are prevalent. Since a number of factors are central to HIVST delivery programs, users' preferences can play an important role when introducing such programs. In the current study, we used the statedpreference approach to explore the acceptability of HIVS $\mathrm{T}$ distribution strategies based on a number of known attributes in Malaysian MSM. Key findings include high levels of acceptability if HIVST distribution programs are optimally organized to accommodate user preferences, notably low-cost models that ensure user anonymity. Findings are useful to guide future HIVST implementation strategies to improve the HIV treatment and prevention cascade in MSM in Malaysia.

\section{Abbreviations}

CBA: Conjoint-based analysis; DCE: Discrete choice experiment; HIVST: HIV self-testing; LGBT: Lesbian, gay, bisexual, and transgender; MSM: Men who have sex with men; MUS: Marginal utility score; PrEP: Pre-exposure prophylaxis; RIS: Relative importance score; WHO: World Health Organization

\section{Acknowledgments}

Not applicable

\section{Authors' contributions}

RS, HA, LPW, and SHL were involved in the conceptualization and the design of the study. SHL carried out the data collection. RS and FLA conducted the analyses. All the authors commented on the final analysis. RS drafted the first draft of the manuscript, and all the authors revised it. All the authors read and approved the final manuscript.

\section{Funding}

This work was supported by a grant from the National Institute on Drug Abuse (K01 DA051346) and a grant from the Fogarty International Center (R21TW011665) to Dr. Shrestha. The funders had no role in the study design, data collection and analysis, decision to publish, or preparation of the manuscript.

\section{Availability of data and materials}

Datasets used and/or analyzed during the current study are available from the corresponding author on reasonable request.

\section{Ethics approval and consent to participate}

The study protocol, along with the consent form, was approved by the University of Malaya Research Ethics Committee (UMREC). Respondents who participated voluntarily completed the IRB-approved online consent form by acknowledging that they understood the purpose, risks, and benefits of the study before initiating the survey.

\section{Consent for publication}

Not applicable.

\section{Competing interests}

The authors declare that they have no competing interests.

\section{Author details}

${ }^{1}$ Section of Infectious Disease, Department of Internal Medicine, Yale School of Medicine, 135 College Street, Suite 323, New Haven, CT 06510, USA. ${ }^{2}$ Centre of Excellence for Research in AIDS (CERiA), Faculty of Medicine, University of Malaya, Kuala Lumpur, Malaysia. ${ }^{3}$ Department of Social \& Preventive Medicine, Faculty of Medicine, University of Malaya, Kuala Lumpur, Malaysia.

Received: 29 April 2020 Accepted: 4 November 2020

Published online: 25 November 2020

\section{References}

1. Ministry of H1. UNAIDS. (2014). 90-90-90: an ambitious treatment target to help end the AIDS epidemic. Geneva: Switzerland; UNAIDS. http://www. unaids.org/en/resources/documents/2014/90-90-901.

2. Joint United Nations Programme on HIV/AIDS (UNAIDS): Prevention Gap Report. In. Geneva, Switzerland; 2016: Accessed on July 14, 2016 at: http:// www.unaids.org/sites/default/files/media_asset/2016-prevention-gapreport_en.pdf.

3. Wei C, Cheung DH, Yan H, Li J, Shi LE, Raymond HF. The impact of homophobia and HIV stigma on HIV testing uptake among Chinese men who have sex with men: a mediation analysis. J Acquir Immune Defic Syndr. 2016;71(1):87-93.

4. Vu L, Tun W, Sheehy M, Nel D. Levels and correlates of internalized homophobia among men who have sex with men in Pretoria, South Africa. AIDS Behav. 2012;16(3):717-23.

5. Schwartz SR, Nowak RG, Orazulike I, Keshinro B, Ake J, Kennedy S, Njoku O, Blattner WA, Charurat ME, Baral SD. The immediate eff ect of the same-sex marriage prohibition act on stigma, discrimination, and engagement on HIV prevention and treatment services in men who have sex with men in Nigeria: analysis of prospective data from the TRUST cohort. Lancet HIV. 2015;2(7):e299-306.

6. Risher K, Adams D, Sithole B, Ketende S, Kennedy C, Mnisi Z, Mabusa X, Baral SD. Sexual stigma and discrimination as barriers to seeking appropriate healthcare among men who have sex with men in Swaziland. J Int AIDS Soc. 2013;16(3 Suppl 2):18715.

7. Fay H, Baral SD, Trapence G, Motimedi F, Umar E, lipinge S, Dausab F, Wirtz A, Beyrer C. Stigma, health care access, and HIV knowledge among men who have sex with men in Malawi, Namibia, and Botswana. AIDS Behav. 2011;15(6):1088-97.

8. Frye V, Wilton L, Hirshfield S, Chiasson MA, Lucy D, Usher D, McCrossin J, Greene E, Koblin B. Preferences for HIV test characteristics among young, black men who have sex with men (MSM) and transgender women: implications for consistent HIV testing. PLoS One. 2018;13(2):e0192936.

9. Ministry of Health Malaysia. (2016). Global AIDS Response Progress Report: Malaysia 2016. Kuala Lumpur: Malaysia. https://www.unaids.org/en/file/11 0936/download?token=DG5OHXljealth Malaysia. Global AIDS Response Progress Report: Malaysia 2016.

10. Shrestha R, Lim SH, Altice FL, Copenhaver M, Wickersham JA, Saifi R, Ab Halim MA, Naning H, Kamarulzaman A. Use of smartphone to seek sexual health information online among Malaysian men who have sex with men (MSM): implications for mHealth intervention to increase HIV testing and reduce HIV risks. J Community Health. 2020;45(1):10-19. 
11. World Health Organization. WHO recommends HIV self-testing - Evidence update and considerations for success. Geneva, Switzerland: World Health Organization; 2019.

12. Johnson CC, Kennedy C, Fonner V, Siegfried N, Figueroa C, Dalal S, Sands A, Baggaley R. Examining the effects of HIV self-testing compared to standard HIV testing services: a systematic review and meta-analysis. J Int AIDS Soc. 2017;20(1):21594.

13. Johnson C, Baggaley R, Forsythe S, van Rooyen H, Ford N, Napierala Mavedzenge S, Corbett E, Natarajan P, Taegtmeyer M. Realizing the potential for HIV self-testing. AIDS Behav. 2014;18(Suppl 4):S391-5.

14. Veloso VG, Vega-Rramirez EH, Hoagland B, Konda KA, Bautista-Arredondo S, Guanira J, Leyva-Flores R, Pimenta C, Benedetti M, Luz P, et al. Safety, early continuation and adherence of same day PrEP initiation among MSM and TGW in Brazil, Mexico and Peru: the ImPrEP Study. In: 10th International AIDS Society Conference: 2019. Mexico City; 2019.

15. Humphrey JM, Naanyu V, MacDonald KR, Wools-Kaloustian K, Zimet GD. Stated-preference research in HIV: a scoping review. PLoS One. 2019;14(10): e0224566.

16. Bridges JF. Stated preference methods in health care evaluation: an emerging methodological paradigm in health economics. Appl Health Econ Health Policy. 2003;2(4):213-24.

17. Ryan M, Scott DA, Reeves C, Bate A, van Teijlingen ER, Russell EM, Napper M, Robb CM. Eliciting public preferences for healthcare: a systematic review of techniques. Health Technol Assess. 2001;5(5):1-186.

18. Shrestha R, Karki P, Altice FL, Dubov O, Fraenkel L, Huedo-Medina T, Copenhaver M. Measuring acceptability and preferences for implementation of pre-exposure prophylaxis (PrEP) using conjoint analysis: an application to primary HIV prevention among high risk drug users. AIDS and Behavior. 2018:22(4):1228-38

19. Sibanda EL, d'Elbée M, Maringwa G, Ruhode N, Tumushime M, Madanhire C, Ong JJ, Indravudh P, Watadzaushe C, Johnson CC, et al. Applying user preferences to optimize the contribution of HIV selftesting to reaching the "first 90" target of UNAIDS fast-track strategy: results from discrete choice experiments in Zimbabwe. J Int AIDS Soc. 2019;22(S1):e25245.

20. Zanolini A, Chipungu J, Vinikoor MJ, Bosomprah S, Mafwenko M, Holmes $\mathrm{CB}$, Thirumurthy H. HIV self-testing in Lusaka Province, Zambia: acceptability, comprehension of testing instructions, and individual preferences for selftest kit distribution in a population-based sample of adolescents and adults. AIDS Res Hum Retrovir. 2018;34(3):254-60.

21. Figueroa C, Johnson C, Verster A, Baggaley R. Attitudes and acceptability on HIV self-testing among key populations: a literature review. AIDS Behav. 2015;19(11):1949-65.

22. Witzel TC, Rodger AJ. New initiatives to develop self-testing for HIV. Curr Opin Infect Dis. 2017;30(1):50-7.

23. Witzel TC, Rodger AJ, Burns FM, Rhodes T, Weatherburn P. HIV self-testing among men who have sex with men (MSM) in the UK: a qualitative study of barriers and facilitators, intervention preferences and perceived impacts. PLoS One. 2016;11(9):e0162713.

24. Wirtz AL, Clouse E, Veronese V, Thu KH, Naing S, Baral SD, Beyrer C. New HIV testing technologies in the context of a concentrated epidemic and evolving HIV prevention: qualitative research on HIV self-testing among men who have sex with men and transgender women in Yangon, Myanmar. J Int AIDS Soc. 2017;20(1):21796.

25. Ryan M, Mclntosh E, Shackley P. Methodological issues in the application of conjoint analysis in health care. Health Econ. 1998;7(4):373-8.

26. IBM SPSS Conjoint 26 [ftp://public.dhe.ibm.com/software/analytics/spss/ documentation/statistics/26.0/en/client/Manuals/IBM_SPSS_Conjoint.pdf]. Accessed 16 July 2020.

27. Ross MA, Avery AJ, Foss AJ. Views of older people on cataract surgery options: an assessment of preferences by conjoint analysis. Qual Saf Health Care. 2003;12(1):13-7.

28. IBM Corp. IBM SPSS statistics for windows, version 23. In. Armonk, NY: IBM Corp.; 2015

29. Lippman SA, Perisse AR, Veloso VG, Sullivan PS, Buchbinder S, Sineath RC, Grinsztejn B. Acceptability of self-conducted home-based HIV testing among men who have sex with men in Brazil: data from an on-line survey. Cad Saude Publica. 2014;30(4):724-34

30. Carballo-Dieguez A, Frasca T, Dolezal C, Balan I. Will gay and bisexually active men at high risk of infection use over-the-counter rapid HIV tests to screen sexual partners? J Sex Res. 2012;49(4):379-87.
31. Tao J, Li M-Y, Qian H-Z, Wang L-J, Zhang Z, Ding H-F, Ji Y-C, Li D-I, Xiao D, Hazlitt $M$, et al. Home-based HIV testing for men who have sex with men in China: a novel community-based partnership to complement government programs. PLoS One. 2014;9(7):e102812.

32. Pan SW, Durvasula M, Ong JJ, Liu C, Tang W, Fu H, Wei C, Wang C, TerrisPrestholt F, Tucker JD. No place like home? Disentangling preferences for HIV testing locations and services among men who have sex with men in China. AIDS Behav. 2019;23(4):847-59.

33. Indravudh PP, Sibanda EL, d'Elbée M, Kumwenda MK, Ringwald B, Maringwa G, Simwinga M, Nyirenda $\sqcup$, Johnson CC, Hatzold K. 'I will choose when to test, where I want to test': investigating young people's preferences for HIV selftesting in Malawi and Zimbabwe. AIDS (London, England). 2017;31(Suppl 3):S203.

34. Lee S-J, Brooks R, Bolan RK, Flynn R. Assessing willingness to test for HIV among men who have sex with men using conjoint analysis, evidence for uptake of the FDA-approved at-home HIV test. AIDS Care. 2013;25(12):1592-8.

35. Golub SA, Gamarel KE. The impact of anticipated HIV stigma on delays in HIV testing behaviors: findings from a community-based sample of men who have sex with men and transgender women in New York City. AIDS Patient Care STDs. 2013;27(11):621-7.

36. Santos G-M, Beck J, Wilson PA, Hebert P, Makofane K, Pyun T, Do T, Arreola S, Ayala G. Homophobia as a barrier to HIV prevention service access for young men who have sex with men. J Acquir Immune Defic Syndr. 2013; 63(5):e167-70.

37. Ren XL, Wu ZY, Mi GD, McGoogan JM, Rou KM, Zhao Y, Zhang N. HIV careseeking behaviour after HIV self-testing among men who have sex with men in Beijing, China: a cross-sectional study. Infect Dis Poverty. 2017;6(1):112.

38. Stevens DR, Vrana CJ, Dlin RE, Korte JE. A global review of HIV self-testing: themes and implications. AIDS Behav. 2018;22(2):497-512.

39. Wood BR, Ballenger C, Stekler JD. Arguments for and against HIV selftesting. HIV AIDS (Auckl). 2014;6:117-26.

40. Zhu X, Zhang W, Operario D, Zhao Y, Shi A, Zhang Z, Gao P, Perez A, Wang J, Zaller N, et al. Effects of a Mobile health intervention to promote HIV selftesting with MSM in China: a randomized controlled trial. AIDS Behav. 2019; 23(11):3129-39.

41. Pant Pai N, Smallwood M, Desjardins L, Goyette A, Birkas KG, Vassal AF, Joseph L, Thomas R. An unsupervised smart app-optimized HIV self-testing program in Montreal, Canada: cross-sectional study. J Med Internet Res. 2018;20(11):e10258.

42. Zhong F, Tang W, Cheng W, Lin P, Wu Q, Cai Y, Tang S, Fan L, Zhao Y, Chen $X$, et al. Acceptability and feasibility of a social entrepreneurship testing model to promote HIV self-testing and linkage to care among men who have sex with men. HIV Med. 2017;18(5):376-82.

43. Stekler J, Wood RW, Swenson PD, Golden M. Negative rapid HIV antibody testing during early HIV infection. Ann Intern Med. 2007;147(2):147-8.

44. Figueroa C, Johnson C, Ford N, Sands A, Dalal S, Meurant R, Prat I, Hatzold K, Urassa W, Baggaley R. Reliability of HIV rapid diagnostic tests for selftesting compared with testing by health-care workers: a systematic review and meta-analysis. Lancet HIV. 2018;5(6):e277-90.

45. Unitaid W. Market and technology landscape: HIV rapid diagnostic tests for self-testing. Geneva: Unitaid, WHO; 2018.

46. Hatzold K, Gudukeya S, Mutseta MN, Chilongosi R, Nalubamba M, Nkhoma C, Munkombwe H, Munjoma M, Mkandawire P, Mabhunu V, et al. HIV selftesting: breaking the barriers to uptake of testing among men and adolescents in sub-Saharan Africa, experiences from STAR demonstration projects in Malawi, Zambia and Zimbabwe. J Int AIDS Soc. 2019;22 Suppl 1(Suppl Suppl 1):e25244.

47. Lippman SA, Gilmore HJ, Lane T, Radebe O, Chen Y-H, Mlotshwa N, Maleke K, Manyuchi AE, Mclntyre J. Ability to use oral fluid and fingerstick HIV selftesting (HIVST) among south African MSM. PLoS One. 2018;13(11):e0206849.

48. Merchant RC, Clark MA, Liu T, Rosenberger JG, Romanoff J, Bauermeister J, Mayer KH. Preferences for oral fluid rapid HIV selftesting among social media-using young black, Hispanic, and white men-who-have-sex-with-men (YMSM): implications for future interventions. Public Health. 2017;145:7-19.

49. Choko AT, MacPherson P, Webb EL, Willey BA, Feasy H, Sambakunsi R, Mdolo A, Makombe SD, Desmond N, Hayes R, et al. Uptake, accuracy, safety, and linkage into care over two years of promoting annual self-testing for HIV in Blantyre, Malawi: a community-based prospective study. PLoS Med. 2015;12(9):e1001873.

50. MacPherson P, Lalloo DG, Webb EL, Maheswaran H, Choko AT, Makombe SD, Butterworth AE, van Oosterhout JJ, Desmond N, Thindwa D, et al. Effect 
of optional home initiation of HIV care following HIV self-testing on antiretroviral therapy initiation among adults in Malawi: a randomized clinical trial. JAMA. 2014;312(4):372-9.

51. Wong HTH, Tam HY, Chan DPC, Lee SS. Usage and acceptability of HIV selftesting in men who have sex with men in Hong Kong. AIDS Behav. 2015; 19(3):505-15.

52. Tun W, Vu L, Dirisu O, Sekoni A, Shoyemi E, Njab J, Ogunsola S, Adebajo S. Uptake of HIV self-testing and linkage to treatment among men who have sex with men (MSM) in Nigeria: A pilot programme using key opinion leaders to reach MSM. J Int AIDS Soc. 2018;21 Suppl 5(Suppl Suppl 5): e25124.

53. Lippman SA, Lane T, Rabede O, Gilmore H, Chen YH, Mlotshwa N, Maleke K, Marr A, McIntyre JA. High acceptability and increased HIV-testing frequency after introduction of HIV self-testing and network distribution among south African MSM. J Acquir Immune Defic Syndr. 2018;77(3):279-87.

54. Dubov A, Fraenkel L, Yorick R, Ogunbajo A, Altice FL. Strategies to implement pre-exposure prophylaxis with men who have sex with men in Ukraine. AIDS Behav. 2018;22(4):1100-12.

55. Shrestha R, Galka J, Azwa I, Lim H, Guadamuz TE, Altice F, Wickersham J. Willingness to use HIV self-testing and associated factors among transgener women in Malaysia. Transgender Health. 2020; (In press).

\section{Publisher's Note}

Springer Nature remains neutral with regard to jurisdictional claims in published maps and institutional affiliations.

Ready to submit your research? Choose BMC and benefit from:

- fast, convenient online submission

- thorough peer review by experienced researchers in your field

- rapid publication on acceptance

- support for research data, including large and complex data types

- gold Open Access which fosters wider collaboration and increased citations

- maximum visibility for your research: over $100 \mathrm{M}$ website views per year

At $\mathrm{BMC}$, research is always in progress.

Learn more biomedcentral.com/submissions 